crash during flight testing at Ellington Air Force Base of a $\$ 2$ million simulation of the module. In any case, the lunar module which is to be tested to within 50,000 feet of the lunar surface during the Apollo 10 mission is said not to be mechanically ideal for a lunar landing, and the time it takes to prepare a launching probably means it is too late now to make any changes. And, despite the proficient handling of the lunar module by McDivitt and Schweickart, Apollo 9 has not been an entire success. It was probably too much to hope that it would be. The sickness which is becoming quite a problem on these flights prevented Schweickart from carrying out the spacewalk properly-and this was intended to be the last exercise outside the spacecraft before the actual lunar landing. At one point, the service propulsion engine also seems to have been hard to start. This is the engine on which the Apollo 11 astronauts will rely to blast them out of lunar orbit for the return home.

Before the critical sequence of events preceding splash-down, the Apollo 9 astronauts were practising the tracking of terrestrial landmarks and doing exercises with the spacecraft systems. NASA is also mollifying critics of its reluctance to promote Earth resources satellites by flying an experiment to obtain multispectral photographs of selected areas on the ground. Four Hasselblad cameras, mounted together with their shutters synchronized, provide four combinations of films and filters matching the combinations planned for the Earth Resources Technology Satellite (ERTS). The cameras fit in the hatch window and the photographs are taken with the spacecraft orientated for vertical photography. The aim is to see how much. information can be gleaned from photographs of the south-west United States where there is a good knowledge of what there is on the ground, and of regions in Mexico and Brazil.

\section{NUCLEAR PROLIFERATION}

\section{International Inspector}

The International Atomic Energy Agency has acquired a new Inspector-General. He is Dr Rudolph Rometsch, a Swiss who is the present managing director of the Eurochemic fuel re-processing plant at $\mathrm{Mol}$ in Belgium. Dr Rometsch takes over six months after the last Inspector-General, Allan D. McKnight, left the agency. Mr McKnight would have been willing to stay on, but wanted a two-year extension of his contract. IAEA was willing to offer only a one-year extension, and Mr McKnight left to take up a post at the Science Policy Research Unit at the University of Sussex.

Dr Rometsch takes over as the IAEA faces its most crucial task, that of policing the non-proliferation treaty, which should come into force during his twoyear term of office. So far, the reactors and experimental installations covered by the IAEA represent only a fraction of those capable of producing material of military importance; when the non-proliferation treaty comes into being, the list will be enormously increased. This is likely to involve Dr Rometsch both in recruiting new staff to undertake inspection procedures, and in negotiating the details of the inspection procedure with the many countries involved. Dr Rometsch's experience in the multi-national Mol plant, which is run by the European Nuclear Energy Agency, is likely to be valuable. A physical chemist to begin with, Dr Rometsch obtained his doctorate from the University of Basle, and worked for the Federal Institute of Technology in Zurich and the CIBA company in Basle before going to $\mathrm{Mol}$ as director of research in 1959. After five years in that position, he became managing director. $\mathrm{He}$ is $\mathbf{5 2}$ this year.

IAEA has also appointed a new director of personnel, Muneer-Uddin Khan, who is from India, and a new representative at the United Nations, Lev Leonidovich Iseav from the USSR.

\section{ENGINEERING \\ Stronger Towers}

THE Greater London Council is to start work next month on strengthening its blocks of flats of the Larsen-Neilsen type, of which Ronan Point is the bestknown example. A method has been devised which is easy to carry out and will cause only slight inconvenience to the tenants. The council has twenty-nine such blocks on nine sites in Inner London-four of seven storeys, twenty of ten storeys, and five of fourteen storeys (the Ronan Point block is twenty-two storeys high). Three of the blocks, at Barley Mow in Tower Hamlets, have been completed only recently and are unoccupied, and it is in one of these that the experiments have been carried out. In outline, the method is to increase the existing strength of the wall to floor joints in each of the 1,276 flats by bolting steel angles to the units at certain junctions. Now that it has been approved by the Ministry of Housing's Technical Panel, the GLC's intention is to start in east London with the first team of men and within three months strengthening work on every site should have been started. It is hoped to complete the work by January 1970.

Since the collapse of part of the Ronan Point block last May, the council has been looking into ways of preventing progressive collapse in its system-built blocks. The gas supply has been taken out of all the blocks (and will not be replaced) and the walls in the ground storey protected against impact from uncontrollable vehicles by the erection of banks and bollards; but, in order to ensure that the blocks can withstand a static pressure of 2.5 pounds per square inch in accordance with a circular sent out by the Ministry of Housing and advice from the Institution of Structural Engineers, the council decided that the joints must be strengthened. It has therefore produced this scheme, which can be completed from inside the building, in conjunction with Phillips Consultants Ltd, the firm of consulting engineers employed by the London Borough of Newham for the Ronan Point block.

The intention is to provide a tensile resistance at each floor level, in both directions, of more than 1,500 pounds per foot, and also to ensure that all panels and all joints at floor level will resist the effects of the stated pressure of 2.5 pounds per square inch. The external wall as strengthened in the unoccupied block is now capable of resisting such pressure all over at any one floor level. In addition, the council has calculated that progressive collapse would be unlikely to occur now in the event of any one panel being completely removed by an explosion or other cause. 